\title{
EDUCAÇÃO DE JOVENS E ADULTOS: ENTRE CASA E TRABALHO UMA OPORTUNIDADE A MAIS POR MEIO DA EDUCAÇÃO A DISTÂNCIA
}

\author{
YOUTH AND ADULT EDUCATION: BETWEEN HOME AND WORK AN EXTRA \\ OPPORTUNITY THROUGH DISTANCE EDUCATION
}

\section{EDUCACIÓN PARA JÓVENES Y ADULTOS: ENTRE EL HOGAR Y EL TRABAJO UNA OPORTUNIDAD ADICIONAL A TRAVÉS DE LA EDUCACIÓN A DISTANCIA}

\author{
Paulo de Sá Filho \\ Titulação do autor: Mestre em Educação Profissional e Tecnológica \\ Instituição: UnB e SENAI - Goiás \\ E-mail: prof.paulo@hotmail.com.br
}

\section{Marco Antônio de Carvalho \\ Titulação do autor: Doutor em Educação \\ Instituição: Instituto Federal Goiano \\ E-mail: marco.carvalho@ifgoiano.edu.br}

\section{Léia Adriana da Silva Santiago}

Titulação do autor: Doutor em Educação.

Instituição: Instituto Federal Goiano

E-mail: leia.adriana@ifgoiano.edu.br

\section{Raqueline da Silva Dias}

Titulação do autor: Especialista em Psicopedagogia

Instituição: SESI - Goiás

E-mail: raqueline.sesi@ sistemafieg.org.br

\section{RESUMO}

Este estudo é o resultado de uma pesquisa bibliográfica baseada em uma análise textual, cujos temas estão relacionados à Educação de Jovens e Adultos (EJA), à Educação a Distância (EaD) e ao Sistema Educacional Brasileiro, fundamentados com a proposta de uma educação crítica, reflexiva e transformadora, logo, emancipatória. Assim, apresenta a EJA como um processo educacional formativo e transformador. O trabalho apresenta a EJA - EaD como uma possibilidade de resgate de indivíduos que não tiveram a oportunidade de estudar no seu devido tempo e que, no presente, ainda apresentam obstáculos adicionais para concluir sua formação, como o trabalho, a família e o tempo escasso para se dedicar aos estudos. Diante desse perfil de população, as análises realizadas apontam que a Educação de Jovens e Adultos a distância é uma proposta possível para solucionar esse problema que há muitos anos impede o avanço do Sistema Educacional Brasileiro. Contudo, o primeiro passo para qualquer transformação socioeconômica e cultural é a conscientização dos envolvidos, o que, neste sentido, justifica a importância deste trabalho.

Palavras-chave: Letrismo a-funcional. Inclusão Social e Digital. Tecnologias. Mundo do Trabalho. 


\begin{abstract}
This study is the result of a bibliographic research based on the analysis of texts whose themes were related to Youth and Adult Education, Distance Learning Education and the Brazilian Educational System, based on proposals of a critical, reflective and transformative education and, therefore, emancipatory. It considers Youth and Adult Education as a formative and transformative educational process. This paper presents Distance Education for Youth and Adult Education as a possibility of rescuing individuals who have not had the opportunity to study in due time and that presently still have additional obstacles to complete their educational formation, such as work, family and the scarce time to dedicate to studies. In the face of this population profile, the data analysis indicates that Distance Education for Youth and Adult Education is a possible proposal to solve this long-term problem which has for many years prevented the Brazilian Educational System from advancing. However, the first step for any socioeconomic and cultural transformation is the awareness of those involved, which, in this sense, justifies the importance of this work.
\end{abstract}

Keywords: Non-Functional Lyricism. Social and Digital Inclusion. Technologies. Workplace.

\title{
RESUMEN
}

Este estudio es el resultado de una investigación bibliográfica basada en un análisis textual, cuyos temas están relacionados con la Educación de Jóvenes y Adultos (EJA), Educación a Distancia $(\mathrm{EaD})$ y el Sistema Educativo Brasileño, basado en las propuestas de una educación crítica, reflexiva y transformadora, por lo tanto emancipadora. Así, presentando la EJA como un proceso educativo formativo y transformador. El trabajo presenta el EJA - EaD como una posibilidad de rescatar a las personas que no tuvieron la oportunidad de estudiar a su debido tiempo y que en la actualidad todavía tienen obstáculos adicionales para completar su capacitación, como trabajo, familia y el tiempo escaso que tienen para dedicarse a los estudios. Dado este perfil de población, los análisis indican que la educación a distancia para jóvenes y adultos es una posible propuesta para resolver este problema que ha impedido el avance del Sistema Educativo Brasileño durante muchos años. Sin embargo, el primer paso para cualquier transformación socioeconómica y cultural es la conciencia de los involucrados, lo que en este sentido justifica la importancia de este trabajo.

Palabras-clave: Lirismo no funcional. Inclusión social y digital. Tecnologías. Mundo del trabajo.

\section{INTRODUÇÃO}

Atualmente, a educação no Brasil tem sido alvo de estudos e pesquisas, visando a seu aperfeiçoamento e à correção de problemas já detectados na formação das crianças, adolescentes e adultos. Essas dificuldades, entretanto, não são recentes e fazem parte de um processo mais complexo que permitiu que perdurasse uma formação deficiente, refletida em jovens e adultos com pouco ou nenhum preparo para as tarefas do cotidiano. Há alguns anos, veio à tona o conceito do analfabetismo funcional, que está um pouco além do analfabetismo 
absoluto, mas que se generaliza em milhares de cidadãos com pouca ou nenhuma instrução, com dificuldade para leitura e compreensão de texto e até para se expressar no convívio profissional e social. Silva (2004) utiliza-se do conceito de letrismo a-funcional, porque compreende que os termos "analfabeto", "analfabetismo" e "analfabetismo funcional" precisam fazer parte do passado da educação no Brasil, pois mostram-se preconceituosos e insuficientes como conceitos no fenômeno do aprendizado e ou não aprendizado da leitura e da escrita da língua materna, uma vez que retira do sujeito toda a sua responsabilidade sobre a sua situação - pois nada se fala sobre o que o sujeito faz do contexto que lhe cerca, salienta as falhas de competências apresentadas por uma pessoa dentro das suas capacidades de utilizar-se da letra e porque "analfabeto" indica um modo pejorativo de referir-se a pessoas que não dominam a leitura e a escrita.

Ao se utilizar dos estudos de J. Biarnés (1996; 1999) e Silva (2004), sinaliza-se que todos possuem uma relação com a letra, com a escrita. Assim, o conceito de letrismo a-funcional permite compreender o lugar da escrita dentro da relação homem e realidade, principalmente quando se está no campo da educação de crianças, jovens e adultos em situação de pouca ou nenhuma escolarização no Brasil. Nesse sentido,

A construção de "letrismo a-funcional" é de grande importância, isto porque, segundo tal conceito, ninguém está totalmente fora da letra ou dentro da letra, procura, portanto, compreender "a" ou "as" funcionalidade(s) que construímos em nossa relação com a letra. Funcionalidades externas que implicam em comunicação com os outros; e funcionalidades internas, na economia psíquica do sujeito. (SILVA, 2004, p. 45).

A escola não pode ser responsabilizada pela formação deficitária de um adulto que abandonou os estudos por precisar garantir o sustento de sua família, mas é um dever social oferecer a esse indivíduo a possibilidade de recuperar o tempo perdido, por meio de cursos de formação que lhe permitam apreender tardiamente o que não o foi no tempo adequado. A Educação de Jovens e Adultos teve início dentro desse cenário, apesar de não ser um conceito novo na educação brasileira. Contudo, tem-se buscado maneiras para resolver essa situação, de tal maneira que se estabeleça políticas e projetos em que oportunizem esses indivíduos com acesso ao saber.

Entretanto, as iniciativas governamentais, que tiveram início em meados do século XX, não conseguiram ainda atender à demanda, mesmo quando baseadas em estudos técnicos especializados e em iniciativas arrojadas, como as propostas por Paulo Freire nas décadas de 1950 e 1960. Com a Resolução CNE/CBE N ${ }^{o} 1$ de 5 de julho de 2000 (BRASIL, RES. CNE/CBE 1, 2000) estabeleceram-se as diretrizes para a avaliação e certificação de jovens e adultos em situação de cursos semipresenciais ou a distância. Inaugurou-se com isso, a oferta 
de EJA na modalidade de Educação a Distância. Num mundo cada vez mais exigente quanto à produtividade e à formação para o mundo do do trabalho, a escolarização torna-se uma necessidade para reduzir as desigualdades sociais e abrir novas oportunidades para jovens e adultos que não conseguiram o aproveitamento adequado no período escolar, qualquer que seja o motivo. Diante disso, este trabalho pretende analisar a importância da EJA por meio da Educação a Distância para o resgate da cidadania de uma parcela da população que não teve oportunidade de estudar no devido tempo. Isso porque faz parte dos hábitos da população em foco o uso dos aparelhos móveis, para o entretenimento quando do deslocamento de casa para o trabalho e no retorno, oportunidade e tempo que poderiam ser utilizados para o acesso às diversas oportunidades de ofertas de cursos on-line, inclusive EJA.

Em 2005, por uma decisão governamental, foi criado, por meio do Decreto 5.478/2005 (BRASIL, Decreto 5.478, 2005), o Programa de Integração da Educação Profissional ao Ensino Médio na Modalidade Educação de Jovens e Adultos - PROEJA. O objetivo era de atender à demanda de jovens e adultos pela oferta de educação profissional técnica de nível médio, e, em muitas situações o próprio Ensino Médio, considerando que tais contingentes populacionais, por razões diversas, não realizaram suas respectivas formações e escolarização no tempo certo - seja por evasão, retenção, dentre outros motivos, que têm sido apontados pelos estudiosos como principais causas do baixo nível de educação formal (sabendo-se que a média brasileira é de 7, 8 anos, nível ao qual muitos nem chegam a ter acesso).

O presente texto se organiza a partir da contextualização da Educação de Jovens e Adultos e suas possibilidades, a partir do uso das ferramentas EaD como elemento facilitador e dinamizador no processo escolarização, visando a minimizar o "letrismo a-funcional", considerando que o primeiro passo para qualquer transformação socioeconômica e cultural é a conscientização dos envolvidos.

\section{A EDUCAÇÃO DE JOVENS E ADULTOS}

Há algumas décadas, a crescente utilização da tecnologia no mundo do trabalho e no cotidiano da sociedade tem exigido da população cada vez mais conhecimento e preparo para a convivência e para a inserção social. Sob o ponto de vista humano, a absorção e a compreensão do grande volume de informações disponibilizadas diariamente pela mídia são fundamentais para que o cidadão possa exercer seu papel político e social com consciência e sabedoria. $\mathrm{O}$ exercício da cidadania exige conhecimento, participação nos fatos e nos acontecimentos que ocorrem em âmbito mundial e que podem, de uma forma ou de outra, influenciar a vida em sociedade. 
No campo profissional, atividades que até recentemente eram oferecidas às pessoas menos qualificadas e tituladas formalmente, agora exigem dos candidatos conhecimentos e habilidades mais específicas. Somente a título de exemplo, cargos como porteiros, serventes de pedreiro, office-boys, dentre outros, hoje possuem como pré-requisito, pelo menos, o Ensino Fundamental completo, já que mesmo esses profissionais terão que lidar com programas de qualidade e de prevenção de acidentes, manuseio de máquinas e equipamentos eletrônicos, preenchimento de formulários, dentre outras tarefas e rotinas funcionais. Em nosso país, a partir do conceito de "letrismo a-funcional", percebe-se que sofreu um decréscimo acentuado no século XX, passando de 85,3\% da população em 1900, para 13,6\% em 2000. Essa redução tem permanecido ao longo dos anos, chegando em $7 \%$ da população com 15 ou mais anos de idade no Brasil em 2017 (BRASIL, IBGE, 2017). Apresenta-se, na Figura 1, a taxa de letrismo afuncional no Brasil, por região.

Figura 1 - Taxa de letrismo a-funcional da população de 15 anos ou mais

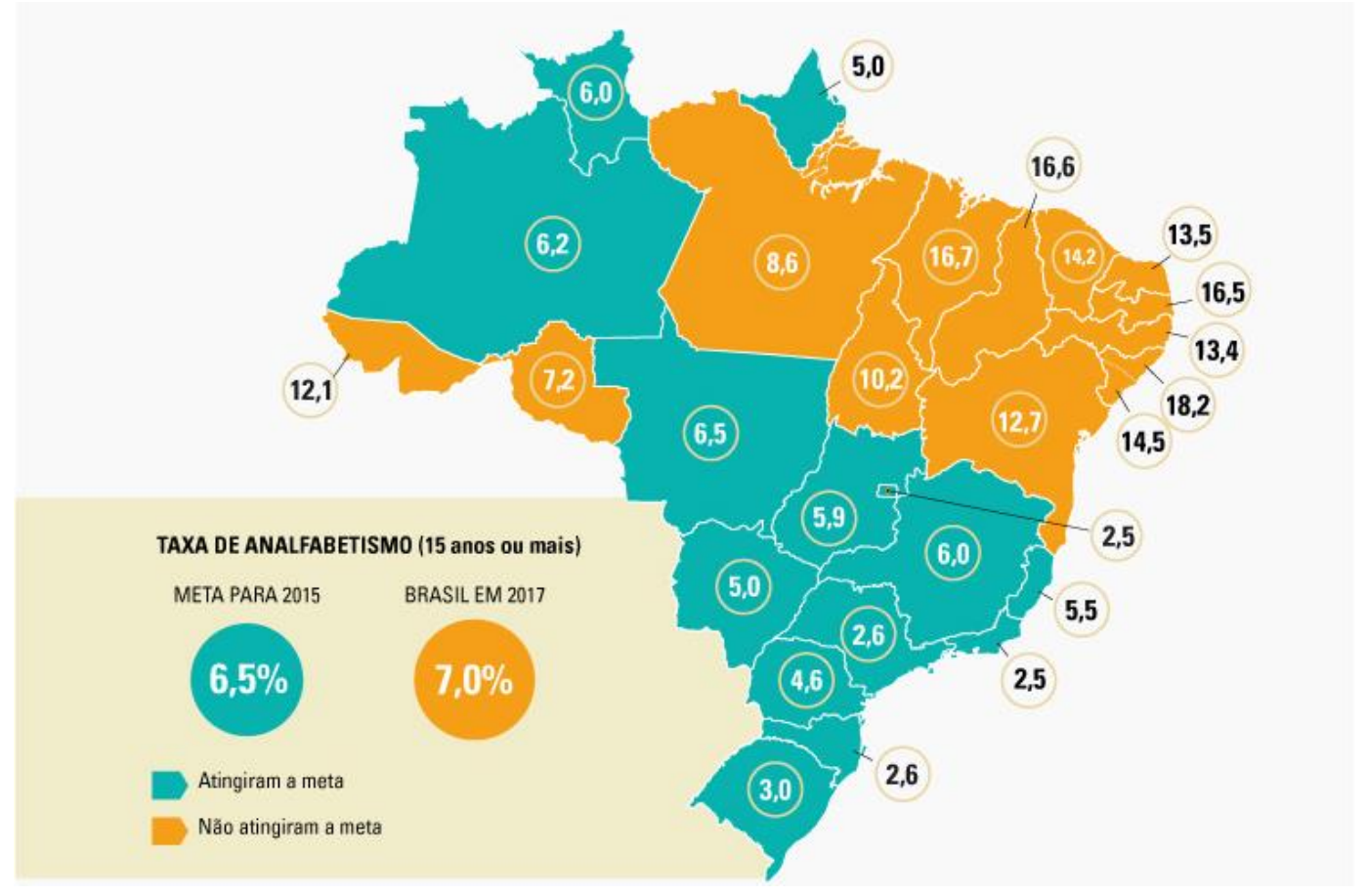

Fonte: (BRASIL, IBGE, 2017) 
De acordo com o Instituto Paulo Montenegro (IPM), que realiza periodicamente um estudo específico sobre o letrismo a-funcional no Brasil, a proporção de brasileiros entre 15 e 64 anos com, no máximo, os 4 ou 5 primeiros anos do Ensino Fundamental, passou de $40 \%$ em 2001-2002 para 21\% em 2018, enquanto a média daqueles que ingressaram ou concluíram o Ensino Médio ampliou-se de $24 \%$ para $40 \%$. No mesmo período, passou de $8 \%$ para $17 \%$ a proporção dos que chegam, concluem ou superam o Ensino Superior (IPM, 2018). A relação entre o letrismo a-funcional e a desigualdade social pode ser verificada pelos demais dados levantados pelo Índice Nacional de Analfabetismo Funcional (IPM-INAF). De acordo com a pesquisa realizada em 2005, $81 \%$ dos indivíduos com letrismo a-funcional pertencem às classes D e E, dentre os quais $41 \%$ encontram-se desempregados. Outros dados também são relevantes: $66 \%$ se declaram "negros", e 22\% não chegaram a completar um ano de estudo. O INAF ainda aponta que 53\% da população entre 14 e 64 anos não conseguiu completar a $8^{\mathrm{a}}$ série, atual nono ano, nível escolar mínimo garantido como direito pela Constituição Federal (GARCIA et al., 2005, p. 8).

Atualmente, essa realidade não é diferente. Os dados expostos pelo "Mapa do letrismo a-funcional", apresentam que as taxas de letrismo a-funcional estão diretamente relacionadas à renda familiar. Nos domicílios que possuem renda superior a 10 salários mínimos, o índice é de apenas $1,4 \%$, enquanto nas famílias que possuem renda inferior a um salário mínimo o índice alcança 29\% (BRASIL, INEP, 2019). As desigualdades regionais, que, de certa forma, refletem a desigualdade social e econômica do país, também podem ser observadas pelos índices de letrismo a-funcional levantados pelo IBGE (BRASIL, IBGE, 2017). Em 2017, as Regiões Nordeste e Norte apresentaram as taxas de letrismo a-funcional mais elevadas, $8 \%$ e 14,5\%, respectivamente, para pessoas com 15 anos ou mais de idade, frente a taxa de 3,5\% nas regiões Sudeste e Sul e a taxa de 5,2\% na região Centro-Oeste (BRASIL, IBGE, 2018).

\section{A SITUAÇÃO DA EDUCAÇÃO DE JOVENS E ADULTOS NO PAÍS}

Tradicionalmente, quando se fala em educação, o senso comum remete à educação de crianças e adolescentes, fase em que esse processo é característico. A idade adulta foi e ainda tem sido concebida como um período de estabilidade e ausência de mudanças, daí a escolarização, nessa faixa etária, ser vista como algo secundário, já que o adulto é compreendido apenas como força de trabalho. Entretanto, esse adulto que é a força produtiva tem participação efetiva no meio social e nas relações interpessoais, trazendo consigo uma complexa história de experiências, conhecimentos e reflexões sobre o mundo real (NATH, 2004, p. 10). 
Os obstáculos encontrados para a escolarização da população acima dos 15 anos são, portanto, de diversas naturezas, principalmente no que diz respeito às percepções equivocadas relacionadas à formação dos professores da EJA e sobre o público-alvo de tais políticas educacionais, conforme aponta Rodrigues e Vitoreti (2014, p. 265),

[...] o professor, para atuar na EJA (E no Proeja) não precisaria de um elevado nível
de formação, haja vista que, por tratar-se de um público que passou muitos anos fora
da escola (que a ela não teve acesso, ou entrou e saiu da escola, ou dela foi excluído),
proveniente das camadas populares, da classe trabalhadora, com algumas pessoas com
dificuldades de aprendizagem, esse profissional poderia ter apenas a graduação ou
especialização, já que, em função dessa clientela, se teria de baixar o nível de
exigência tanto no trabalho pedagógico, como na aprendizagem dos conteúdos, na
formação científica e pedagógica etc. Essa concepção é equivocada, pois esses alunos
demandam um professor de excelência, que exerça a docência comprometido com a
classe trabalhadora, que tenha, entre outros aspectos, a preocupação em adequar sua
prática aos sujeitos com os quais atua, em articular os saberes cotidianos dos
educandos aos conhecimentos técnico-científicos, o que torna esses esforços ainda
mais complexos e específicos.

Tais concepções equivocadas podem ser explicadas, pois, até o início do Período Republicano, a Educação de Jovens e Adultos restringia-se ao ensino profissionalizante, oferecido em classes noturnas e ministrados por professores sem qualquer preparo específico para atender a esse público. Apesar de, em 1916, Olavo Bilac ter alertado para o problema do letrismo a-funcional no país, que à época atingia $70 \%$ da população, somente a partir da década de 1930 é que começaram os esforços no sentido de criar políticas públicas dirigidas para sua redução, motivadas principalmente pelo início da industrialização e pela necessidade de formação de mão de obra mais qualificada. (LOPES; SOUSA, 2005, p. 75). A Constituição de 1934 incluiu pela primeira vez a educação de adultos como dever do Estado, estendendo a isso o ensino primário integral, gratuito e de frequência obrigatória. As primeiras campanhas de alfabetização de jovens e adultos, desencadeadas nas décadas de 1940 e 1950, não obtiveram os resultados esperados, principalmente em função da inadequação das metodologias utilizadas e dos curtos períodos dedicados a esse tipo de ensino (alfabetização em 3 meses, seguida do ensino primário ministrado em dois períodos de 7 meses) (LOPES SOUSA, 2005, p. 76). Mesmo assim, os movimentos de entidades internacionais, como a Organização das Nações Unidas para a Educação, Ciência e Cultura (UNESCO), tiveram influência positiva, consolidando a alfabetização de adultos como uma questão nacional.

No início da década de 1960, Paulo Freire introduziu novos paradigmas na EJA, valorizando a cultura local e desenvolvendo um método revolucionário de alfabetização, principalmente voltado para as comunidades rurais. O método de Paulo Freire teve repercussão internacional e deu origem ao Plano Nacional de Alfabetização, aprovado em 1964, e apoiado 
por diversas entidades da sociedade civil. Esse plano, entretanto, não chegou a ser colocado efetivamente em prática em virtude do golpe militar, que desarticulou os núcleos que estavam sendo preparados para essa finalidade, sob a suspeita de que poderiam ameaçar a ordem então instalada.

Apesar da repressão, os governos militares criaram o Movimento Nacional de Alfabetização (MOBRAL), cujas bases se assentavam nos princípios de Paulo Freire, sendo logo seguido, segundo Lopes e Sousa (2005, p. 76), pela criação do Ensino Supletivo, através da Lei $\mathrm{n}^{\circ}$ 5.692, de 1971, voltado para a escolarização regular de adolescentes e adultos que não tivessem conseguido concluir os estudos na idade apropriada. Entre 1970 e 1980, os índices de letrismo a-funcional levantados pelos censos, apontaram uma redução de 33,7\% para 25,9\% da população, abaixo dos objetivos iniciais desses projetos, fenômeno historicamente observado quando se trata de plano de governos para a implementação de políticas educacionais aos que vivem do trabalho. Após o movimento de redemocratização do país, a partir do início da década de 1980, a EJA sofreu diversas alterações. O MOBRAL foi extinto, dando lugar à Fundação EDUCAR. Em 1988, a Constituição Federal garantiu o ensino fundamental obrigatório e gratuito inclusive para jovens e adultos. No governo Collor, em 1990, com a finalidade de reduzir despesas, a Fundação EDUCAR foi extinta e a EJA foi gradualmente transferida para os estados e municípios.

Somente na segunda metade da década de 1990, a EJA volta a ser alvo de preocupação do Governo Federal. Em 1996, foi promulgada a Lei $n^{o} 9394$ (Lei de Diretrizes e Bases da Educação - LDB) (BRASIL, LDB, 1996), com uma seção específica para a EJA e, em 1997, foi criado o Programa de Alfabetização Solidária, uma organização não governamental, que, em parceria com estados, municípios, empresas privadas e instituições de Ensino Superior oferece a formação de alfabetizadores e já atendeu mais de 5 milhões de alunos em todos o país (HADDAD; DI PIERRO, 2000). A partir de 2000, a responsabilidade pela EJA foi repassada para os municípios, através do Projeto de Escolarização de Jovens e Adultos, retornando, em 2003, à esfera federal, com a criação do programa Brasil Alfabetizado, que apoia projetos desenvolvidos por Estados, Municípios e ONGs para a alfabetização e formação de alfabetizadores em todo o país. Além das entidades governamentais, diversas empresas e instituições sociais passaram a desenvolver projetos de alfabetização e educação continuada para o público jovem e adultos, como forma de minimizar, via educação formal, as desigualdades sociais e melhorar os indicadores socioeconômicos dessa população.

Além do Alfabetização Solidária, que atualmente trabalha em parceria com 188 instituições de ensino superior (IES) e com 166 empresas privadas, destacam-se, ainda, os 
trabalhos da Fundação Banco do Brasil (BB Educar), que, desde 1992, já alfabetizou mais de 350 mil pessoas em 17 unidades da Federação, inspirado nos fundamentos de Paulo Freire. Todavia, o Brasil ainda se configura como um país com elevado índice de letrismo a-funcional. Dos que se encontram nessa situação de letrismo a-funcional, em sua maioria são jovens e adultos pobres e negros. As políticas públicas voltadas para a EJA, até o presente momento, não conseguiram eliminar essa problemática educacional. Ainda mais que nos últimos anos, ocorreu uma redução no número de matrículas nessa modalidade, conforme demonstrado no Gráfico 1, retirado da página do Observatório do Plano Nacional de Educação (OPNE).

\section{Gráfico 1 - Porcentagem de matrículas de Educação de Jovens e Adultos no Ensino Fundamental, integradas à Educação Profissional}

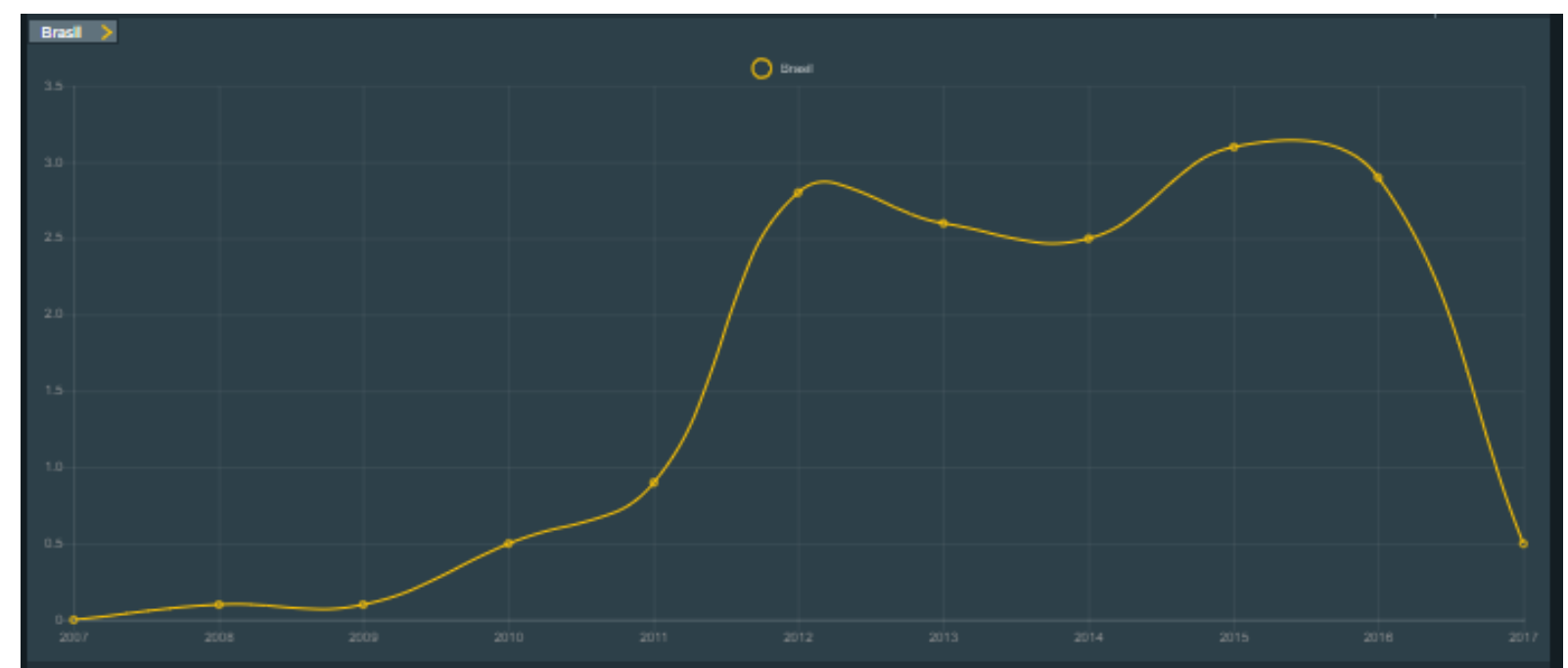

Fonte: Observatório do PNE, 2018

$\mathrm{Na}$ descrição desse gráfico, é demonstrado, na série histórica, iniciando-se em 2007, que não houve matrícula de EJA de Ensino Fundamental integradas à Educação Profissional, e que houve um crescimento contínuo entre os anos de 2009 e 2012. Nos demais anos, houve oscilação, chegando em 2017, dado mais atual apresentado, com 0,5\% das matrículas, quase 12 mil alunos nesse tipo de modalidade. Entretanto, cabe ressaltar que essa quantidade está muito longe do cumprimento da meta estabelecida no Plano Nacional de Educação (PNE), que é de oferecer, no mínimo, 25\% (vinte e cinco por cento) das matrículas de educação de jovens e adultos, nos ensinos fundamental e médio, na forma integrada à educação profissional (OPNE, 2019). Diante da atual situação, pensar em uma proposta que implemente a EJA de uma maneira célere e que oportunize a formação dos indivíduos nas mais diversas situações e realidades econômicas e sociais é fundamental. 
Considerando que, dentre os principais fatores intervenientes nas diversas formas de evasão escolar, ressaltam-se as dificuldades de conciliar trabalho e estudos presenciais, acrescidas da questão logística, ambas impactantes nas dificuldades de manutenção e subsistência dos segmentos sociais que vivem do trabalho - condições apontadas em diversos estudos como capitais para as famílias em que ambos os pais igualmente estudaram pouco e têm que trabalhar, muitas vezes em situações precárias de renda e habitação, deixando os filhos sem o acompanhamento adequado das atividades escolares. Isso leva aos reiterados fracassos escolares e posterior abandono definitivo no período adequado às suas faixas etárias, agravando, assim, o quadro de letrismo a-funcional. Em decorrência dessas questões, surge a necessidade da EJA por meio da Educação a Distância como uma possibilidade a ser construída.

\section{O LETRISMO A-FUNCIONAL NO BRASIL}

No Brasil, em 2017, a taxa de letrismo a-funcional das pessoas de 15 anos ou mais de idade foi estimada em 7,0\% (11,5 milhões de analfabetos), o que significa uma redução de 2\%, ou seja, aproximadamente 330 mil pessoas, ao observarmos os dados de 2016 (BRASIL, IBGE, 2018). Apesar desse cenário, as taxas são altas para as idades mais avançadas, como demonstra o Gráfico 2.

\section{Gráfico 2 - Taxa de letrismo a-funcional das pessoas de 15 anos ou mais de idade}

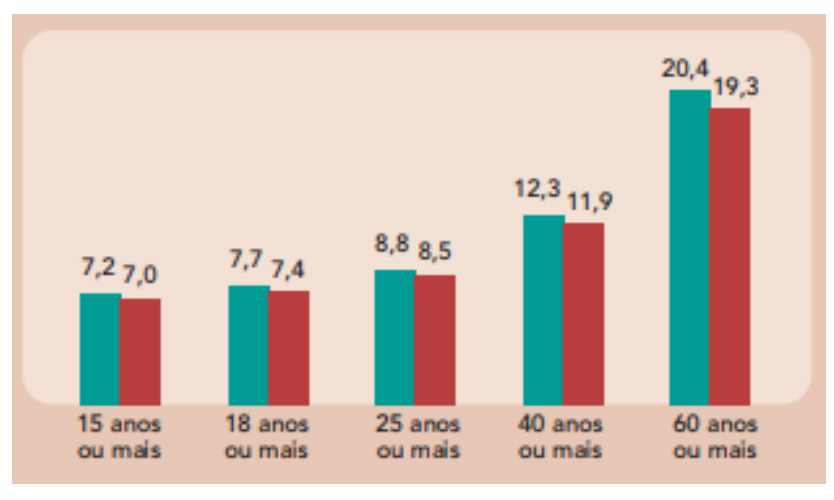

Fonte: IBGE, Diretoria de Pesquisas, Coordenação de Trabalho e Rendimento, Pesquisa Nacional por Amostra de Domicílios Contínua 2016-2017.

Diante do perfil do público-alvo e de interesse do presente trabalho, População Economicamente Ativa - PEA, que já está inserido no mundo do trabalho e, com isso, precisa conciliar trabalho e estudo, pensar formas e recursos que facilitem esse processo é primordial. Nessa perspectiva, a Educação a Distância tem surgindo como possibilidade, por dar autonomia ao educando para gerir seu processo de ensino-aprendizagem, por meio da flexibilização do tempo e fornecendo recursos tecnológicos para a comunicação e socialização do conhecimento 
entre docente e educando, bem como educando e docente. Além disso, conforme já mencionado anteriormente, o tempo gasto no translado casa-trabalho-casa, com entretenimentos em aparelhos de comunicação móveis, pode ser igualmente utilizado como fonte de informações e conhecimentos, inclusive acadêmico-científicos. Assim, articular a EaD e EJA, surge como uma proposta a ser implementada.

A EJA por meio da modalidade EaD, está sendo utilizada como uma possibilidade, não apenas como uma busca de conhecimentos, mas no sentido de inserção e de intervenção que os jovens e adultos, que são alunos dessa proposta, podem promover na sociedade. Dessa maneira, a EJA - EaD tem como principal desafio democratizar o acesso desses estudantes não só ao ensino e ao conhecimento gerado ao longo do tempo pela humanidade, mas. em especial, o acesso aos novos meios e recursos de aprender e ensinar estruturados pelas novas tecnologias, tais como: realidade aumentada, microlearning, comunicação por vídeo, celular e etc. Nessa perspectiva, essa modalidade de ensino tem sido adotada em diferentes contextos educacionais, sendo aceita em proposta governamentais há alguns anos, tais como no Plano Nacional de Educação - PNE (BRASIL, PNE, 2010) e Parâmetros Curriculares Nacionais - PCN'S (BRASIL, PCN, 1997). Tais ações promovem uma aceitação desse tipo de formação tanto para docentes, quanto para os possíveis educandos. Com isso, impulsiona sua oferta a toda sociedade.

A EJA a distância pode ser vista, então, como uma forma de melhorar o nível de escolaridade desses sujeitos jovens e adultos, promovendo, assim, a melhoria da condição desses trabalhadores, além de produzir um impacto na produtividade e desenvolvimento social quando incluídos nas novas tecnologias da informação e comunicação. Dessa maneira, essa modalidade oportuniza ao indivíduo que realiza esse tipo de formação a inclusão educacional e a inclusão tecnológica, inserindo, com isso, o sujeito de uma forma mais igualitária na sociedade atual. Essa afirmação torna-se verdadeira, porque a EaD mostra-se como um veículo atraente e inovador, ainda mais quando aliado a práticas de acessibilidade a alunos de diversas áreas do saber e contextos sociais, considerando como referência que a democracia digital é uma meta do sistema educacional brasileiro. Nessa proposta,

\footnotetext{
A Educação de Jovens e Adultos a distância significa, então, a possibilidade de articular no trabalho pedagógico, a realidade sociocultural dos estudantes, $\mathrm{o}$ desenvolvimento e os interesses específicos de cada educando, bem como os conhecimentos acumulados historicamente pela humanidade, a qual todos têm direito de acesso, de acordo com as políticas fundamentais que democratizam o saber (SOUZA; FERNANDES; BARRETO, 2014, p. 11).
} 
Ressalta-se que não se trata de se ater somente à educação de jovens e adultos, mas à educação como um todo, pois o ciberespaço amplamente divulgado e de acesso facilitado implica o fortalecimento de práticas educacionais, visto que a educação é capaz de libertar, no que se entende como liberdade para aprender. Esse conhecimento não precisa ser necessariamente um conhecimento escolarizado, mas que busque envolver a dimensão da formação do ser autônomo, global, que aprende de forma contextualizada, integrada a seu tempo, às tecnologias, aos novos modelos de interação educacional, dotado de conhecimentos formalizados e institucionalizados. Por meio desse espectro, entendemos que a EJA - EaD surge como uma ponte que liga aqueles que estão às margens da sociedade atual, a qual valoriza as tecnologias de informação e comunicação e busca promover o avanço tecnológico. Assim, urge promover esse tipo de formação, para a melhoria do Sistema Educacional Brasileiro e da sociedade de uma maneira geral.

\section{CONSIDERAÇÕES FINAIS}

Apesar da evolução quantitativa apresentada pela Educação no Brasil nos últimos anos, as políticas oficiais ainda são insuficientes para atender à demanda qualitativa e para suprir as lacunas deixadas no passado. Os índices de letrismo a-funcional caíram, mas esses números não correspondem totalmente à realidade, uma vez que não incluem aqueles cidadãos que são analfabetos funcionais, ou seja, ainda não dominam estratégias para utilizar os conhecimentos em seu cotidiano. De maneira geral, o problema da educação é bastante complexo e envolve diversas frentes que precisam ser trabalhadas simultaneamente para que os resultados sejam eficazes. Um aluno que sai da escola sem ter aprendido o conteúdo mínimo esperado é um sinal de alerta para professores de uma maneira geral, especificamente aqueles mal treinados ou sem recursos para executar um trabalho bem feito, material didático desatualizado, instalações inadequadas, currículos defasados ou distantes da realidade dos alunos, falta de motivação, entre outros aspectos.

A Educação de Jovens e Adultos é uma tentativa de resgate dessa parcela da população que não teve oportunidade de estudar no seu devido tempo e que, no presente, ainda apresenta obstáculos adicionais para poder concluir sua formação, como o trabalho, a família, o tempo escasso para se dedicar aos estudos, dentre tantos. Por esse motivo, deve-se oportunizar esse tipo de formação por meio da $\mathrm{EaD}$, já que os perfis desses estudantes são de jovens e adultos inseridos no mundo do trabalho e trazem consigo uma experiência de vida que ultrapassa as limitações inerentes ao ensino infantil. 


\section{REFERÊNCIAS}

BATISTA, A. P.; SOUZA FILHO, M.; OLIVEIRA, I. P. B.; SOUZA, H. A. G.; MELO, J. P. Possibilidades e desafios da Educação Física como componente curricular no processo de expansão regional do Instituto Federal de Educação, Ciência e Tecnologia do Rio Grande do Norte - IFRN. Holos, ano 30, vol. 4, 2014.

BIARNÈS, J. Jeunes et adults en échec, mais encore! Education, Paris, vol. 24, mar/maio. 1996.

BIARNÈS, J Universalité, Diversité, sujet dans l'espace pédagogique. Paris: L'Harmattan, 1999.

BRASIL. Ministério da Educação. Resolução CNE/CBE n.1 de 5 de julho de 2000. Estabelece as Diretrizes Curriculares Nacionais para a Educação de Jovens e Adultos. Diário Oficial da União: Seção 1, Brasília, DF, n. 1, p. 18, 19 jul. 2000a.

BRASIL. Ministério da Educação. Conselho Nacional de Educação/Câmara de Educação Básica. Resolução n. 01 de 05 de julho de 2000. Brasília: MEC, 2000b. Estabelece as Diretrizes Curriculares Nacionais para a Educação e Jovens e Adultos. Disponível em: http://portal.mec.gov.br/cne/arquivos/pdf/CEB012000.pdf. Acesso em: 18 mar. 2019.

BRASIL. Ministério da Educação. Secretaria de Ensino Fundamental. Proposta Curricular para a Educação de Jovens e Adultos: segundo segmento do ensino fundamental. Brasília: MEC, 2002.

BRASIL. Ministério da Educação. Instituto Nacional de Estudos e Pesquisas Educacionais Anísio Teixeira (INEP). Mapa do Analfabetismo no Brasil. Brasília: MEC/INEP, 2003.

BRASIL. Ministério da Educação. Instituto Nacional de Estudos e Pesquisas Educacionais Anísio Teixeira (INEP). Estudo detalha situação do analfabetismo no País. 2003. Disponível em: http://inep.gov.br/artigo/-/asset_publisher/B4AQV9zFY7Bv/content/estudodetalha situacao-do-analfabetismo-no-pais/21206. Acesso em: 18 mar. 2019.

BRASIL. Ministério da Educação. Instituto Nacional de Estudos e Pesquisas Educacionais Anísio Teixeira (INEP). Censo da Educação Superior 2004 - Resumo Técnico. (Versão preliminar), Brasília: 2005.

BRASIL. Decreto 5.478 de 24 de junho de 2005. Institui, no âmbito das instituições federais de educação tecnológica, o Programa de Integração da Educação Profissional ao Ensino Médio na Modalidade de Educação de Jovens e Adultos - PROEJA. Diário Oficial da União: Seção 1, Brasília, DF, n. 121, p. 4, 27 jun. 2005. Disponível em: http://pesquisa.in.gov.br/imprensa/jsp/visualiza/index.jsp?jornal=1\&pagina $=4 \&$ data $=27 / 06 / 20$ 05. Acesso em: 18 jul. 2019.

BRASIL. Ministério da Economia. Instituto Brasileiro de Geografia e Estatística (IBGE). Educação no Brasil. 2018. Disponível em: http://www.ibge.gov.br/ibgeteen/pesquisas/ educacao.html. Acesso em: 18 mar. 2019. 
BRASIL. Ministério da Economia. Instituto Brasileiro de Geografia e Estatística (IBGE). Analfabetismo cai em 2017, mas segue acima da meta para 2015. 2018. Disponível em: https://agenciadenoticias.ibge.gov.br/agencia-noticias/2012-agencia-denoticias/noticias/21255-analfabetismo-cai-em-2017-mas-segue-acima-da-meta-para-2015. Acesso em: 18 mar. 2019.

BRASIL. Ministério da Economia. Instituto Brasileiro de Geografia e Estatística (IBGE)). PNAD Contínua: Educação 2017. 2018. Disponível em: https://biblioteca.ibge.gov.br/visualizacao/livros/liv101576_informativo.pdf. Acesso em: 18 mar. 2019.

BRASIL. Ministério da Economia. Instituto Brasileiro de Geografia e Estatística (IBGE). IBGE Educa: Educação no Brasil. 2018. Disponível em: http://www.ibge.gov.br/ibgeteen/pesquisas/ educacao.html. Acesso em 18 mar. 2019.

BRENNAND, E. G. G.; BRENNAND, E. G. Inovações Tecnológicas e a Expansão do Ensino Superior no Brasil. Revista Lusófona de Educação, 2012, vol. 21, p. 179-198.

GARCIA, M. et. al. $5^{\mathbf{0}}$ Indicador Nacional de Analfabetismo Funcional. São Paulo: Instituto Paulo Montenegro, 2005.

HADDAD, S.; DI PIERRO, M. C. Escolarização de jovens e adultos. Revista Brasileira de Educação, 2000, n. 14, p. 108-194. Disponível em: http://www.scielo.br/pdf/rbedu/n14/n14a07.pdf. Acesso em: 25 jul. 2019.

INSTITUTO PAULO MONTENEGRO (IPM). Indicador de Analfabetismo Funcional: Pesquisa gera conhecimento, o conhecimento transforma. 2018. Disponível em: http://acaoeducativa.org.br/blog/publicacoes/indicador-de-alfabetismo-funcional-inaf-brasil2018. Acesso em:18 mar. 2019.

LOPES, S. P.; SOUSA, L. S. EJA: Uma Educação Possível ou Mera Utopia? Revista Alfabetização Solidária (Alfasol), vol. 5, p. 75-80, set. 2005.

NATH, M. A. Alfabetização de Jovens e Adultos em Cascavel: Uma História em Construção. 2004. Monografia (Especialização em Fundamentos da Educação). Universidade do Oeste do Paraná (UNIOESTE) - Cascavel (PR), 2004.

OBSERVATÓRIO DO PLANO NACIONAL DE EDUCAÇÃO (OPNE) 10. EJA Integrada à Educação Profissional. Movimento Todos pela Educação. 2019. Disponível em http://www.observatoriodopne.org.br/indicadores/metas/10-eja-integrada-a-educacaoprofissional/indicadores. Acesso em: 20 abr. 2019

RODRIGUES, M. E.; VITORETI, J. M. B. PROEJA dos institutos federais de educação, ciência e tecnologia do estado de Goiás: práticas pedagógicas e formação continuada de professores. Educativa, Goiânia, v. 17, n. 1, p. 253-282, jan./jun. 2014. 
SILVA, N. Da inadequação do termo analfabetismo: da necessidade de novos conceitos para a compreensão do ensino e aprendizagem da leitura e da escrita em Língua Portuguesa. Pátio. Revista Pedagógica (Porto Alegre), Rio Grande do Sul, v. 29, p. 44-46, 2004. 